Jurnal Indonesia Sosial Teknologi: p-ISSN: 2723 - 6609

e-ISSN : 2745-5254

Vol. 2, No. 11 November 2021

\title{
PENGARUH BUDAYA ORGANISASI, LINGKUNGAN KERJA DAN KOMPENSASI TERHADAP KINERJA KARYAWAN DENGAN KEPUASAN KERJA SEBAGAI VARIABEL INTERVENING (STUDI KASUS WAROENG SPESIAL SAMBAL (SS) CABANG YOGYAKARTA)
}

\author{
Dies Diminica Selviana Siki \\ Jurusan Manajemen, Fakultas Ekonomi, Universitas Sarjanawiyata Tamansiswa \\ Yogyakarta \\ Email: diesdominica0798@gmail.com
}

\begin{abstract}
Abstrak
Seiring dengan perkembangan industry di era globalisasi ini menimbulkan persaingan yang ketat. Dengan berbagai persaingan tersebut menuntut perusahaan untuk siap menghadapi tantangan agar dapat mempertahankan kelangsungan hidup perusahaan. Penelitian ini bertujuan untuk menguji apakah kinerja budaya organisasi, lingkungan kerja dan kompensasi berpengaruh berpengaruh terhadap kinerja karyawan dengan kepuasan kerja sebagai variabel intervening. Penelitian mengambil sampel pada Waroeng Spesial Sambal (SS) Cabang Yogyakarta. Metode penarikan sampel adalah dengan nonprobabilitas sampling dan teknik penarikan sampel menggunakan aksidental. Pengumpulan data dilakukan dengan kuesioner atau angket. Jumlah kuesioner yang diolah adalah sebanyak 97 kuesioner. Data analisis dengan menggunakan path analysis. Hasil penelitian menunjukan bahwa masingmasing variabel berpengaruh. Budaya organisasi secara langsung maupun dimediasi berpengaruh positif dan signifikan terhadap kinerja karyawan. Namun lingkkungan kerja tidak berpengaruh terhadap kinerja karyawan baik secara langsung maupun melalui kepuasan kerja. Kompensasi secara langsung berpengaruh posistif dan signifikan terhadap kinerja karyawan. Lingkungan kerja dan kompensasi tidak dimediasi oleh kepuasan kerja. Temuan ini juga mendukung bahwa kepuasan kerja berpengaruh positif dan signifikan terhadap kinerja karyawan.
\end{abstract}

Kata kunci: budaya organisasi; lingkungan kerja; kompensasi; kepuasan kerja \& kinerja karyawan.

\section{Abstract}

Along with the development of industry in this era of globalization, it creates intense competition. With these various competitions, companies are required to be ready to face challenges in order to maintain the company's survival. This study aims to examine whether the performance of organizational culture, work environment and compensation have an effect on employee performance with job satisfaction as an intervening variable. The study took samples at Waroeng Special Sambal (SS) Yogyakarta Branch. Sampling method is by non-probability sampling and sampling technique using accidental. Data was collected by means of a questionnaire or questionnaire. The number of questionnaires that were processed were 97 questionnaires. Data analysis using path analysis. The results showed that each 
Pengaruh Budaya Organisasi, Lingkungan Kerja dan Kompensasi Terhadap Kinerja Karyawan dengan Kepuasan Kerja Sebagai Variabel Intervening (Studi Kasus Waroeng Spesial Sambal (SS) Cabang Yogyakarta)

variable had an effect. Organizational culture directly or mediated has a positive and significant effect on employee performance. However, the work environment does not affect employee performance either directly or through job satisfaction. Compensation directly has a positive and significant effect on employee performance. Work environment and compensation are not mediated by job satisfaction. This finding also supports that job satisfaction has a positive and significant effect on employee performance.

Keywords: organizational culture; work environment; compensation; job satisfaction \& employee performance.

\section{Pendahuluan}

Seiring dengan perkembangan industry diera globalisasi ini mwnimbulkan persaingan yang ketat. Dengan berbagai persaingan dengan berbagi persaingan tersebut menuntut perusahaan untuk siap menghadapi tantangan agar dapat mempertahankan kelangsunngan hidup perusahaan. Perusahaan sebagai organisasi bisnis harus siap berkompetisi. Keberhasilan dan kegagalan sebuah perusahaan tidak terlepas dari faktor sumber daya manusia. Untuk meningkatkan keberhasilan dan mengantisipasi kegagalan maka dalam manajemen perusahaan perlu adanya pengelolaan sumber daya manusia.

Sumber daya manusia merupakan bagian yang memegang peranan penting dalam sebuah organisasi. dalam aktivitas sebuah perusahaan ada banyak hal yang berpengaruh terhadap kesuksesaan perusaan. Kinerja atau performa karyawan merupakan salah satu faktor yang sangat berpengaruh terhadap kesuksesan sebuah perusahaan. karena dengan adanya perkembangan era globslisasi ini, kompetisi global telah menaikan standar kinerja dengan beragam dimensi, organisasi, manajemen, sumber daya manusia, kualitas, biaya, produk, dan system. Hanya dengan menerima tantangan ini, perusahaan dapat meningkatkan sumber daya manusianya dan data menajamkan ketterampilan mereka.

Menurut Anwar Purba Mangkunegara mengatakan bahwa kinerja adalah hasil kerja secara kualitas dan kuantitas yang dicapai oleh seorang karyawan dalam melaksanakan tugasnya sesuai dengan tanggung jawab yang diberikan (Rini, Maria, \& Syaharuddin, 2018). Karyawan merupakan factor produksi yang penting sebagai penentu kinerja perussahaan secara keseluruhan. Dari defenisi-defenisi ini dapat disimpulkan bahwa kinerja adalah hasil akhir yang dicapai oleh seorang karyawan untuk mendapatkan imbal balik dari perusahaan atau organisasi tempat ia bekerja dalam jangka waktu tertentu. Ada beberapa factor yang berpengaruh terhadap kinerja karyawan diantaraya budaya organisasi, lingkungan kerja, kompensasi, kepuasan kerja dan motivasi. Ada pula factor lain yang didukkung oleh penelitian dari (Setiawan \& Dewi 2014) mengatakan bahwa ada beberapa fakyor yang berpengaruh terhadap kinerja karyawan diantaranya kompensasi, motivasi, kepemimpinan dan lingkungan.

Kepuasan merupakan sesuatu yang sangat personal, dimana yang biasa merasakan hanya orang yang bersangkutan dan mempunyai sifat yang tidak selalu sama antara orang yang satu dengan yang lain. Dalam (Dwijayanti \& Kartika 2015), kepuasan merupakan 
sifat yang tidak selalu sama antara orang yang satu dengan yang lain yang bersifat personal, dimana hal tersebut yang merasakan hanya orang yang berdangkutan.

Di era sekarang konsep budaya digunakan sebagai konsep budaya organisasi menurut (Ahmed \& Shafiq 2014). Dengan budaya organisasi terjadi hubungan timbal balik dari masing-masing orang dalam organisasi baik berupa perintah, saran, pendapat maupun kritik. Menurut (Moulana et al. 2017) menyatakan bahwa lingkungan kerja yang bersih dan rapi tidak hanya menyokong kesehatan dan kesejahteraan umum para pegawai tapi juga kerapian dan keakuratan pekerjaan. Dalam meningkatkan kinerja karyawan tercapai yang merupakan tujuan perusahaan maka perusahaan berkewajiban untuk memberikan lingkungan kerja yang nyaman bagi karyawannya. Lingkungan kerja berhubungan dengan kondisi internal maupun eksternal yang dapat mempengaruhi kinerja sehingga dengan demikian diharapkan pekerjaan dapat terselesaikan dengan lebih cepat dan lebih baik. (Lestary \& Harmon 2017) mengemukakan bahwa lingkungan kerja yang merupakan salah satu faktor penentu kinerja karyawan yang menjadi salah satu kunci sukses perusahaan demi mencapai kesuksesan. Kompensasi juga merupakan salah satu faktor yang meningkatkan keinginan karyawan untuk berkomitmen terhadap organisasi. Kompensasi tidak berfungsi sebagai balas jasa semata, namun lebih dari itu, kompensasi dapat meningkatkan karyawan agar tetap dalam organisasi dan dapat diajak bersama-sama bertanggung jawab terhadap jalannya organisasi dan disampig itu kompensasi yang adil akan menimbulkan rasa memiliki terhadap organisasi, yang akhirnya berdampak pada tingginya komitmen karyawan pada organisasinya.

Prestasi karyawan adalah salah satu sumbangan yang sangat berpengaruh terhadap perusahaan. Dengan memiliki karyawan yang berprestai perusahaan dapat lebih meningkatkan kinerja perusahaan. Dengan itu, setiap perusahaan tentu selalu mengharapkan prestasi yang baik dari setiap karyawannya, karena dengan prestasi karyawan yang baik tentu akan mmberikan sumbangan yang optimal terhadap perusahaan. Sering terjadi kinera karyawan menurun dikarenakan adanya ketidak nyamanan dalam bekerja,

Berdasarkan permasalahan diatas, maka penelliti tertarik untuk meneliti permasalahan yang berhubungan dengan budaya organisasi, lingkungan kerja, kompensasi dan kepuasan kerja dalam mempengaruhi kinerja karyawan dengan judul, "Pengaruh Budaya Organiasai, Lingkungan Kerja, dan Kompensasi terhadap Kinerja Karyawan dengan Kepuasan Kerja sebagai variable intervening (Studi pada Waroeng SS Yogyakarta)".

Ada pula tujuan dari penelitian ini adalah sebagai berikut : 1) Untuk mengetahui pengaruh budaya organisasi terhadap kepuasan kerja, 2) Untuk mengetahui pengaruh lingkungan kerja terhadap kepuasan kerja, 3) Untuk mengetahui pengaruh kompensasi terhadap kepuasan kerja, 4) Untuk mengetahui pengaruh budaya organiasai, lingkungan kerja, dan kompensasi terhadap kepuasan kerja, 5) Untuk mengetahui pengaruh budaya organisasi terhadap kinerja karyawan, 6) Untuk mengetahui pengaruh lingkungan kerja terhadap kinerja karyawan, 7) Untuk mengetahui pengaruh kompensasi terhadp kinerja karyawan, 8) Untuk mengetahui pengaruh budaya organisasi, lingkungan kerja, dan 
Pengaruh Budaya Organisasi, Lingkungan Kerja dan Kompensasi Terhadap Kinerja Karyawan dengan Kepuasan Kerja Sebagai Variabel Intervening (Studi Kasus Waroeng Spesial Sambal (SS) Cabang Yogyakarta)

kompensasi terhadap kinerja karyawan, 9) Untuk mengetahui pengaruh kepuasan kerja terhadap kinerja karyawan, 10) Untuk mengetahui pengaruh budaya organisasi terhadap kinerja karyawan dengan kepuasana kerja sebagai varibel intervening, 11) Untuk mengetahui pengaruh lingkungan kerja terhadap kinerja karyawan dengan kepuasana kerja sebagai varibel intervening, 12) Untuk mengetahui pengaruh kompensasi terhadap kinerja karyawan dengan kepuasana kerja sebagai varibel intervening.

\section{Metode Penelitian}

Variabel independent dalam penelitian ini adalah budaya organisasi, lingkungan kerja, dan kompensasi. Variabrel dependen adalah kinerja karyawan, sedangkan variabel intervening adalah kepuasn kerja.

\section{Populasi dan Sampel}

Populasi pada penelitian ini berjumlah 3600 orang. Teknik pengambilan sampel yang digunakan adalah teknik aksidental sampling. Teknik aksidental adalah bagian dari teknik non probability sampling.

Sumber data yang digunakandalam penelitian ini adalah data primer. Data primer adalah data yang diperoleh penulis melalui observasi atau pengamatan langsung dari perusahaan, baik melalui observasi, kuesioner, dan wawancara secara langsung dengan pemimpin dnan staff perusahaan sesuai dengan kebutuhan dalam penelitian ini. Data primer diperoleh dengan cara mendistribusikan kuesioner kepada karyawan Waroeng SS Yogyakarta.

\section{Hasil dan Pembahasan}

Analisis Kuiantitatif

Tabel 4.13 Rekapitulasi Hasil Uji Hipotesis

\begin{tabular}{lll}
\hline No & Hipotesis & Keterangan \\
\hline 1 & $\begin{array}{l}\text { Ada pengaruh signifikan dari dari Budaya Organisai } \\
\text { terhadap kepuasan kerja pada Waroeng SS Jogja }\end{array}$ & Terbukti \\
\hline 2 & $\begin{array}{l}\text { Ada pengaruh signifikan dari dari Lingkungan Kerja } \\
\text { terhadap kepuasan kerja pada Waroeng SS Jogja }\end{array}$ & Terbukti \\
\hline 3 & $\begin{array}{l}\text { Ada pengaruh signifikan dari dari Kompensasi terhadap } \\
\text { kepuasan kerja pada Waroeng SS Jogja }\end{array}$ & Terbukti \\
\hline 4 & $\begin{array}{l}\text { Ada pengaruh signifikan dari dari Budaya Organisai, } \\
\text { Lingkungan Kerja, dan Kompensasi terhadap kepuasan } \\
\text { kerja pada Waroeng SS Jogja }\end{array}$ & Terbukti \\
\hline 5 & $\begin{array}{l}\text { Ada pengaruh signifikan dari dari Budaya Organisai } \\
\text { terhadap kinerja karyawan pada Waroeng SS Jogja }\end{array}$ & Terbukti \\
\hline 6 & $\begin{array}{l}\text { Ada pengaruh signifikan dari dari Lingkungan Kerja } \\
\text { terhadap kinerja karyawan pada Waroeng SS Jogja }\end{array}$ & Tidak \\
\hline 7 & $\begin{array}{l}\text { Ada pengaruh signifikan dari dari Kompensasi terhadap } \\
\text { kinerja karyawan pada Waroeng SS Jogja }\end{array}$ & Terbukti \\
\hline
\end{tabular}




\begin{tabular}{|c|c|c|}
\hline 8 & $\begin{array}{l}\text { Ada pengaruh signifikan dari dari Budaya Organisai, } \\
\text { Lingkungan Kerja, dan Kompensasi terhadap kinerja } \\
\text { karyawan pada Warnerja karyawan Waroeng SS Jogja }\end{array}$ & Terbukti \\
\hline 9 & $\begin{array}{l}\text { Ada pengaruh signifikan dari dari Kepuasan Kerja } \\
\text { terhadap kinerja karyawan pada Waroeng SS Jogja }\end{array}$ & Terbukti \\
\hline 10 & $\begin{array}{l}\text { Ada pengaruh signifikan dari Budaya Organisasi terhadap } \\
\text { Kinerja Karyawan memalui kepuasan kerja sebaagi } \\
\text { variable intervening pada Waroeng SS Jogja }\end{array}$ & Terbukti \\
\hline 11 & $\begin{array}{l}\text { Ada pengaruh signifikan dari Lingkungan Kerja terhadap } \\
\text { Kinerja Karyawan memalui kepuasan kerja sebaagi } \\
\text { variable intervening pada Waroeng SS Jogja }\end{array}$ & $\begin{array}{l}\text { Tidak } \\
\text { Terbukti }\end{array}$ \\
\hline 12 & $\begin{array}{l}\text { Ada pengaruh signifikan dari Kompensasi terhadap Kinerja } \\
\text { Karyawan memalui kepuasan kerja sebagai variable } \\
\text { intervening pada Waroeng SS Jogja }\end{array}$ & $\begin{array}{l}\text { Tidak } \\
\text { Terbukti }\end{array}$ \\
\hline
\end{tabular}

\section{Pembahasan}

Penelitian ini terdiri dari 97 responden yang merupakan karyawan dari beberap outlet Waroenng SS Jogja. Mayoritas responden dalam penelitian ini adalah berjenis kelamin perempuan sebanyak 52,6\%. Dari segi usia, mayoritas responden berusia 25 tahun - 30 tahun sebanyak $38,1 \%$, sedangkan mayoritas status pernikahan adalah yang belum menikah sebesar 52,6\%. Mayoritas tingkat pendidikan responden dalam peneliltian ini adalah lulusan SMA sebanyak 94,8\%. Sedangkan untuk lama bekerja responden dalam penelitian ini mayoritas sudah bekerja selama 1 tahun - 5 tahun sebanyak $51,5 \%$.

\section{Pengaruh Budaya Organisasi terhadap Kepuasan Kerja}

Budaya Organisasi bepengaruh signifikan terhadap kepuasan kerja, terbukti. Hal ini dibuktikan dengan nilai $\mathrm{t}$ hitung sebesar 3,113>t table 1,1985 dengan nilai probabilitas sebesar 0,002 $<0,05$. Ada pula pengaruh positif dari budaya organisasi terhadap kepuasan kerja di Waroeng SS Jogja dibuktikan dengan nilai koefisien hasil regresi yaitu 0,370. Nilai koefisien 0,370 ini juga bukti peningkatan kepuasan kerja karyawan setiap ada peningkatan budaya organisasi sebesar satu-satuan. Artinya semakin baik budaya organisasi dalam perusahaan Waroeng SS ini makan semakin besar pula kepuasan kerja karyawan juga akan semakin tinggi.

Hal ini sejalan dengan penelitian terdahulu yang dilakukan oleh "The Influence of Work Environment and Organizational Culture on Work Satisfaction and Lecture Performance of Management Informantion and Computer in Sulawesi" koefisien pengaruh budaya organisasi terhadap kepuasan kerja sebesar 0,255 dengan nilai t hitung sebesar 3,297 pada taraf signifikan 0,000. Koefisien tersebut menunjukan bahwa budaya organisasi berpengaruh positif terhadap kepuasan kerja. Artinya peningkatan budaya organisasi akan diikuti oleh peningkatan kepuasan kerja dengan asumsi factor lain yang mempengaruhi ukuran kepuasan kerja dianggap sebagai konstanta statistic ( 
Pengaruh Budaya Organisasi, Lingkungan Kerja dan Kompensasi Terhadap Kinerja Karyawan dengan Kepuasan Kerja Sebagai Variabel Intervening (Studi Kasus Waroeng Spesial Sambal (SS) Cabang Yogyakarta)

2017) . Penelitian lain yang mendukung adalah diantaranya menurut (Gorap et al.,2019), (Suryajiwangga 2017), (Susetyo et al., 2014) dan (Sugiyarti 2012).

\section{Pengaruh Lingkungan Kerja terhadap Kepuasan Kerja}

Lingkungan Kerja bepengaruh signifikan terhadap kepuasan kerja, terbukti. Hal ini dibuktikan dengan nilai $\mathrm{t}$ hitung sebesar 2,115>t table 1,1985 dengan nilai probabilitas sebesar $0,037<0,05$. Ada pula pengaruh positif dari lingkungan kerja terhadap kepuasan kerja di Waroeng SS Jogja dibuktikan dengan nilai koefisien hasil regresi yaitu 0,260. Nilai koefisien 0,260 ini juga bukti peningkatan kepuasan kerja karyawan setiap ada peningkatan lingkungan kerja sebesar satu-satuan. Artinya semakin baik lingkungan kerja dalam perusahaan Waroeng SS ini makan semakin besar pula kepuasan kerja karyawan juga akan semakin tinggi.

Penelitian ini didukung oleh beberapa penelitian terdahulu diantaranya yang berjudul "The Influence of Work Environment and Organizational Culture on Work Satisfaction and Lecture Performance of Management Informantion and Computer in Sulawesi" dengan koefisien pengaruh lingkungan kerja terhadap kepuasan kerja sebesar 0,328 dengan nulai sebesar 3,320 pada taraf signifikan sebesar 0,000. Koefisien tersebut menunjukan bahwa variable lingkungan kerja berpengaruh positif terhadaap kepuasan kerja. Artinya peningkatan pada lingkungan kerja akan diikuti oleh peningkatan kepuasan kerja dengan asumsi factor-faktor lain yang mempoerngaruhi besar kecilnya kepuasan kerja dianggao konstan. Pengaruh t statistic lingkungan kerja terhadap kepuasan kerja sebesar 3,320 denga signifikan 0,000 atau dibawah 0,05 artinya lingkungan kerja berpengaruh signifikan terhadap kepuasan kerja (Soetikno, 2017).

\section{Pengaruh Kompensasi terhadap Kepuasan Kerja}

Kompensasi bepengaruh signifikan terhadap kepuasan kerja, terbukti. Hal ini dibuktikan dengan nilai t hitung sebesar 5,928 > t table 1,1985 dengan nilai probabilitas sebesar $0,000<0,05$. Ada pula pengaruh positif dari kompensasi terhadap kepuasan kerja di Waroeng SS Jogja dibuktikan dengan nilai koefisien hasil regresi yaitu 0,371. Nilai koefisien 0,371 ini juga bukti peningkatan kepuasan kerja karyawan setiap ada peningkatan kompensasi sebesar satu-satuan. Artinya semakin baik kompensasi dalam perusahaan Waroeng SS ini makan semakin besar pula kepuasan kerja karyawan juga akan semakin tinggi. Kepuasan kerja. Hal ini dibuktikn dengan nilai t hitung sebesar 5,298 dengan nilai proabilitas sebesar. Ada pula pengaruh dari kompensasi terhadap kepuasan kerja waroeng SS Jogja dibuktikan dengan nilai koefisien hasil regresi yaitu 0,371 .

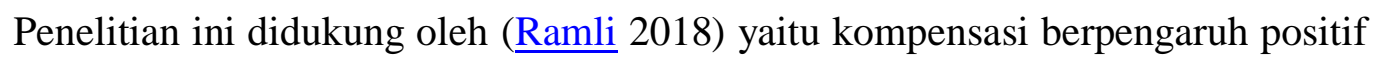
dan signifikan terhadap kepuasna kerja. Hal yang sama juga dibuktikan oleh (Setyorini et al., 2018) ditunjukan dengan koefisien jalur positif sebesar 0,668 denga t-statistik sebesar 3,221 (t-statistik > 1,96), hasil ini menunjukan pengaruh positif dan signifikan terhadap kepuasan kerja terbukti secra empiris. Sama halnya dengan peneitian dari (Juliarti et al., (2018), (Dwijayanti \& Kartika 2015), dan (PH \& Sudiyarningsih 2018), hasil 
penelitiannya menujukan bahwa kompensasi berpengaruh positif dan signifikan terhadap kepuasan kerja dan hasil penelittian ini mendukung hasil penelitian yang dilakukan oleh (Sugiyarti 2012).

\section{Pengaruh Budaya Organisasi, Lingkungan Kerja, dan Kompensasi terhadap Kepuasan Kerja}

Budaya Orgaisasi Lingkungan Kerja dan Kompensasi berpengaruh signifikan terhadap kepuasan kerja, terbukti. Hal ini dibuktikan dengan F hitung sebesar 55,811 dengan nilai signifikansi sebesar 0,000. Sedangkan nilai Adjusted R Square yang sebesar 0,631 menunjukan bahwa pengaruh budaya organisasi, lingkungan kerja dan kompensasi terhadap kepuasan kerja karyawan sebesar $63,1 \%$ dan sisanya 36,9\% dipengaruhi oleh variable lainnya.

Menurut (PH \& Sudiyarningsih 2018) dalam penelitiannya di Fakultas Ekonomi Universitas 17 Agustus 1945 Semarang, mengatakan bahwa secara simultan adanya pengaruh budaya organisasi, lingkunga kerja, dan kompensasi terhadap kepuasan kerja. Begitu pula dengan penelitian dari (Sugiyarti 2012).

\section{Pengaruh Budaya Organisasi terhadap Kinerja Karyawan}

Budaya organisasi bepengaruh positif dan signifikan terhadap kinerja karyawan, terbukti. Hal ini dibuktikan dengan nilai thitung sebesar 4,771 > t table 1,1985 dengan nilai probabilitas sebesar $0,000<0,05$. Ada pula pengaruh positif dari budaya organisasi terhadap kinerja karyawan di Waroeng SS Jogja dibuktikan dengan nilai koefisien hasil regresi yaitu 0,471. Nilai koefisien 0,471 ini juga bukti peningkatan kinerja karyawan setiap ada peningkatan budaya organisasi sebesar satu-satuan. Artinya semakin baik budaya organisasi dalam perusahaan Waroeng SS ini makan semakin besar pula kinerja karyawan juga akan semakin tinggi.

Menurut (Awadh et al., 2013) dan (Soetikno 2017) budaya organisasi berpengaruh positif dan signifikan terhadap kinerja karyawan.

\section{Pengaruh Lingkungan Kerja terhadap Kinerja Karyawan}

Lingkungan Kerja bepengaruh positif dan signifikan terhadap kinerja karyawan, tidak terbukti. Hal ini dibuktikan dengan nilai t hitung sebesar 1,671>t table 1,1985 dengan nilai probabilitas sebesar 0,171>0,05. Tidak ada pengaruh signifikan dari lingkungan kerja terhadap kinerja karyawan di Waroeng SS Jogja dibuktikan dengan nilai koefisien hasil regresi yaitu 0,097. Nilai koefisien 0,097 ini juga bukti peningkatan kinerja karyawan setiap ada peningkatan lingkungan kerja sebesar satu-satuan. Artinya lingkungan kerja tidak berpengaruh signifikan terhadap kinerja karyawan dalam perusahaan Waroeng SS secara parsial.

Penelitian ini didukung oleh penelitian dari (Pawirosumarto et al., 2017) mengatakan bahwa lingkungan kerja tidak berpengaruh terhadap kinerja karyawan.

\section{Pengaruh Kompensasi terhadap Kinerja Karyawan}


Pengaruh Budaya Organisasi, Lingkungan Kerja dan Kompensasi Terhadap Kinerja Karyawan dengan Kepuasan Kerja Sebagai Variabel Intervening (Studi Kasus Waroeng Spesial Sambal (SS) Cabang Yogyakarta)

Kompensasi bepengaruh signifikan terhadap kinerja karyawan, terbukti. Hal ini dibuktikan dengan nilai thitung sebesar 5,290 > t table 1,1985 dengan nilai probabilitas sebesar $0,000<0,05$. Ada pula pengaruh positif dari kompensasi terhadap kineja karyawan di Waroeng SS Jogja dibuktikan dengan nilai koefisien hasil regresi yaitu 0,275 . Nilai koefisien 0,275 ini juga bukti peningkatan kinerja karyawan setiap ada peningkatan kompensasi sebesar satu-satuan. Artinya semakin baik kompensasi dalam perusahaan Waroeng SS ini makan semakin besar pula kinerja karyawan juga akan semakin tinggi.

Menurut (Sopiah, 2013) kompensasi berpengaruh positif dan signifikan terhadap kinerja karyawan secara langsung.

\section{Pengaruh Budaya Organisasi, Lingkungan Kerja, dan Kompensasi terhadap Kinerja Karyawan}

Budaya Orgaisasi Lingkungan Kerja dan Kompensasi berpengaruh signifikan terhadap kinerja karyawan, terbukti. Hal ini dibuktikan dengan F hitung sebesar 55,775 dengan nilai signifikansi sebesar 0,000. Sedangkan nilai Adjusted R Square yang sebesar 0,673 menunjukan bahwa pengaruh budaya organisasi, lingkungan kerja dan kompensasi terhadap kinerja karyawan sebesar $67,3 \%$ dan sisanya $32,7 \%$ dipengaruhi oleh variable lainnya.

Menurut (Dewi 2021) dan (PH \& Sudiyarningsih 2018) mengatakan bahwa secara bersamaan atau simultan berpengaruh terhadap kinerja karyawan.

Budaya organisasi, lingkungan kerja, dan kompensasi memberikan kontribusi diatas $60 \%$ untuk peningkatan kinerja karyawan yaitu sebesar $67 \%$. Hal ini membuktikan bahwa dengan adanya budaya organisasi yang mendukung, lingkunngan kerja yang nyaman dan kondusif serta didukung dengan kompensasi yang menunjang maka kinerja karyawan di Waroeng SS akan meningkat. Kinerja karyawan merupakan salah satu hal penting perusahaan karena sangat mempengaruhi produktivitas perusahaan.

\section{Pengaruh Kepuasan Kerja terhadap Kinerja Karyawan}

Kepuasan Kerja karyawan bepengaruh signifikan terhadap kinerja karyawan, terbukti. Hal ini dibuktikan dengan nilai t hitung sebesar 12,475 > t table 1,1985 dengan nilai probabilitas sebesar $0,000<0,05$. Ada pula pengaruh positif dari kepuasn kerja karyawan terhadap kineja karyawan di Waroeng SS Jogja dibuktikan dengan nilai koefisien hasil regresi yaitu 0,694. Nilai koefisien 0,694 ini juga bukti peningkatan kinerja karyawan setiap ada peningkatan kepuasn kerja karyawan sebesar satu-satuan. Artinya semakin baik kepuasan kerja karyawan dalam perusahaan Waroeng SS ini makan semakin besar pula kinerja karyawan juga akan semakin tinggi.

Dalam penelitian (Suryajiwangga 2017) mengatakan bahwa semakin tinggi kepuasan karyawan semakin baik kinerja karyawan, sebaliknya tingkat kepuasan karyawan rendah maka kinerja karyawan menjadi buruk.

\section{Pengaruh Budaya Organisasi terhadap Kinerja Karyawan melalui Kepuasan Kerja sebagai variable intervening}


Budaya organisasi berpengaruh signifikan terhadap kinerja dengan kepuasan kerja sebagai variable intervening, terbukti. Diketahui pengaruh budaya organisasi secara langsung terhadap kinerja karyawan 0,474 sedangkan pengaruh tidak langsung dari budaya organisai melalui kepuasan kerja sebesar 0,258. Maka pengaruh total yang diberikan $\mathrm{X} 1$ terhadap $\mathrm{Y}$ adalah pengaruh langsung ditambah dengan pengaruh tidak langsung yaitu $:(\mathrm{X} 1 \rightarrow \mathrm{Y})+(\mathrm{X} 1 \rightarrow \mathrm{Z} \rightarrow \mathrm{Y})=0,474+0,258=0,732$. Artinya pengaruh langsung budaya orgaisasi lebih besar dari pada pengaruh tidak langsung budaya organisasi terhadap kinerja karyawan melalui kepuasan kerja. Hasil ini menunjukan bahwa secara tidak langsung X1 melalui Z memiliki pengaruh signifikan terhadap Y.

Menurut hasil penelitian dari (Henry Syauta et al., 2012) kompensasi berpengaruh positif dan signifikan terhadap kinerja karyawan melalui kepuasan kerja. Begitu pula dengan penelitian dari (PH \& Sudiyarningsih 2018) dan (Suryajiwangga (2017).

\section{Pengaruh Lingkungan Kerja terhadap Kinerja Karyawan melalui Kepuasan Kerja sebagai variable intervening}

Lingkungan kerja tidak bepengaruh signifikan terhadap kinerja karyawan melalui kepuasan kerja sebagai variable intervening, tidak terbukti. Diketahui pengaruh lingkungan kerja secara langsung terhadap kinerja karyawan 0,175 sedangkan secara tidak langsung melalui kepuasan kerja 0,184. Maka pengaruh total yang diberikan X1 terhadap $\mathrm{Y}$ adalah pengaruh langsung ditambah dengan pengaruh tidak langsung yaitu : $(\mathrm{X} 2 \rightarrow \mathrm{Y})+(\mathrm{X} 2 \rightarrow \mathrm{Z} \rightarrow \mathrm{Y})=0,175+0,184=0,359$. Artinya pengaruh langsung lingkungan kerja lebih besar dari pada pengaruh tidak langsung lingkungan kerja terhadap kinerja karyawan melalui kepuasan kerja. Hasil menunjukan bahwa secara tidak langsung $\mathrm{X} 2$ melalui $\mathrm{Z}$ memiliki pengaruh signifikan terhadap $\mathrm{Y}$.

Penelitian ini didukung oleh penelitian dari (Pawirosumarto et al., 2017) yang mengatakan bahwa lingkungan kerja tidak berpengaruh terhadap kinerja karyawan.

\section{Pengaruh Kompensasi terhadap Kinerja Karyawan melalui Kepuasan Kerja sebagai variable intervening}

Kompensaai tidak berpengaruh signifikan terhadap kinerja karyawan dengan kepusan kerja sebagai variable intervening, tidak terbukti. Diketahui pengaruh kompensasi terhadap kinerja karyawan secara langsung memiliki nilai koefisien sebesar 0,384 sedangkan pengaruh komepensasi terhadap kinerja karyawan melalui kepuasasn kerja memiliki nilai koefisien sebesasar 0,325. Maka pengaruh total yang diberikan X1 terhadap $\mathrm{Y}$ adalah pengaruh langsung ditambah dengan pengaruh tidak langsung yaitu : $(\mathrm{X} 3 \rightarrow \mathrm{Y})+(\mathrm{X} 3 \rightarrow \mathrm{Z} \rightarrow \mathrm{Y})=0,384+0,325=0,709$. Artinya pengaruh langsung kompensasi lebih besar dari pada pengaruh tidak langsung kompensasi terhadap kinerja karyawan melalui kepuasan kerja. Hasil menunjukan bahwa secara tidak langsung X3 melalui $\mathrm{Z}$ memiliki pengaruh tidak signifikan terhadap $\mathrm{Y}$. 
Pengaruh Budaya Organisasi, Lingkungan Kerja dan Kompensasi Terhadap Kinerja Karyawan dengan Kepuasan Kerja Sebagai Variabel Intervening (Studi Kasus Waroeng Spesial Sambal (SS) Cabang Yogyakarta)

\section{Kesimpulan}

Hasil penelitian yang telah dilakukan mengenai pengaruh budaya organisasi, lingkungan kerja, dan kompensasi terhadap kinerja karyawan dengan kepuasan kerja sebagai variabel intervening pada Waroeng Spesial Sambal Cabang Yogyakarta dapat ditarik kesimpulan berdasarkan rumusan masalah, tujuan penelitian, hipotesis penelitian dan hasil penelitian serta pembahasan maka dapat disimpilkan bahwa secara simultan budaya organisasi, lingkungan kerja dan kompensasi dapat berpengaruh terhadap kepuasan kerja dan kinerja karyawan. Secara parsial budaya organisasi, lingkungan kerja dan kompensasi berpengaruh terhadap kepuasan kerja. Sedangkan terhadap kinerja karyawan budaya organisasi dan kompensasi secara langsung berpengaruh positif dan signifikan, lingkungan kerja berpengaruh positif tetapi tidak signifikan. Kepuasan kerja berpengaruh positif dan signifikan terhadap kinerja karyawan. Budaya organisasi berpengaruh positif dan signifikan terhadap kinerja karyawan dengan kepuasan kerja sebagai variabel intervening, sedangkan lingkungan kerja dan kompensasi tidak berpengaruh terhadap kinerja karyawan dengan kepuasan kerja sebagai variabel intervening. 


\section{Bibliografi}

Ahmed, Mashal, \& Shafiq, Saima. (2014). Impact of organizational culture on organizational performance: a case study of Telcom Sector. Global Journal of Management and Business Research: A Administration and Management, 3(3), 975-985. Retrieved from https://www.researchgate.net/publication/323799766.

Awadh, Alharbi Mohammad, Alyahya, \& Saad, Mohammed. (2013). Impact of organizational culture on employee performance. International Review of Management and Business Research, 2(2), 168-175. https://doi.org/10.17010/pijom/2018/v11i6/128442.

Dewi, Galuh Yuliana. (2021). Pengaruh budaya organiasi, lingkungan kerja, dan kompensasi terhadap kinerja karyawan Kota Mojokerto. Jurnal Ekonomi Syariah, 6(2), 98-112. https://doi.org/10.30736/jesa.v6i2.100.

Dwijayanti, Made Nensy, \& Kartika, A. .. Sagung. (2015). Pengaruh kompensasi dan lingkungan kerja terhadap kepuasan kerja karyawan pada Perusahaan Daerah Air Minum Tirta Mangutama Badung. E-Jurnal Manajemen Unud, 4(12), 4274-4301. Retrieved from https://www.neliti.com/id/publications/255292/.

Gorap, Stefaniae Inggried, Haerani, Siti, \& Hakim, Wardhani. (2019). Pengaruh budaya organisasi, komitmen organisasi, dan kompensasi terhadap kinerja pegawai melalui kepuasan kerja sebagai variabel intervening (Studi Pada Dinas Kesehatan Daerah Kota Tomohon). Hasanuddin Journal of Applied Business and Entrepreneurship, 2(2), 100-114. Retrieved from https://media.neliti.com/media/publications/279986. https://doi.org/10.26487/hjabe.v2i2.203.

Henry Syauta, Jack, Afnan Troena, Eka, Setiawan, Margono, \& Solimun. (2012). The Influence of Organizational Culture, Organizational Commitment to Job Satisfaction and Employee Performance (Study at Municipal Waterworks of Jayapura, Papua Indonesia). International Journal of Business and Management Invention ISSN (Online, 1(1), 69-76. Retrieved from www.ijbmi.org

Juliarti, Putu Ayu Diah, Agung, Anak Agung Putu, \& Sudja, I. Nengah. (2018). Effect of compensation and work environment on employee performance with employee job satisfaction as an intervening variable. International Journal of Contemporary Research and Review, 9(03), 20553-20562. https://doi.org/10.15520/ijcrr/2018/9/03/460.

Lestary, Lyta, \& Harmon, Harmon. (2017). Pengaruh lingkungan kerja terhadap kinerja karyawan. Jurnal Riset Bisnis Dan Investasi, 3(2), 94-103. https://doi.org/10.35697/jrbi.v3i2.937.

Moulana, Ferry, Sunuharyo, Bambang Swasto, \& Utami, Hamidah Nayati. (2017). Pengaruh lingkungan kerja terhadap kinerja karyawan melalui variabel mediator motivasi kerja (Studi pada Karyawan PT. Telkom Indonesia,Tbk Witel Jatim Selatan, Jalan A. Yani, Malang). Jurnal Administrasi Bisnis S1 Universitas 
Pengaruh Budaya Organisasi, Lingkungan Kerja dan Kompensasi Terhadap Kinerja Karyawan dengan Kepuasan Kerja Sebagai Variabel Intervening (Studi Kasus Waroeng Spesial Sambal (SS) Cabang Yogyakarta)

Brawijaya, 44(1), 178-185. Retrieved from https://media.neliti.com/media/publications/87793.

Pawirosumarto, Suharno, Sarjana, Purwanto Katijan, \& Gunawan, Rachmad. (2017). The effect of work environment, leadership style, and organizational culture towards job satisfaction and its implication towards employee performance in Parador hotels and resorts, Indonesia. International Journal of Law and Management, 59(6), 13371358. https://doi.org/10.1108/IJLMA-10-2016-0085.

PH, Prihatin Tiyanto, \& Sudiyarningsih, Sri. (2018). Pengaruh budaya organisasi, lingkungan kerja , kompensasi terhadap kinerja melalui kepuasan kerja pada Pegawai Sekretariat Daerah Kabupaten Blora. Jurnal Ilmiah UNTAG Semarang, 7(1), 91-101. Retrieved from http://203.89.29.50/index.php/sa/article/viewFile/702/675.

Ramli, Abdul Haeba. (2018). Compensation, job satisfaction and employee performance in Health Services. Business and Entrepreneurial Review, 18(2), 177-186. https://doi.org/10.25105/ber.v18i2.5335.

Rini, Elfiana Septiya, Maria, Siti, \& Syaharuddin. (2018). Pengaruh lingkungan kerja, budaya organisasi dan stres kerja terhadap kinerja pegawai di Puskesmas Merancang Kabupaten Berau. 20(2), 81-86. https://doi.org/10.29264/jfor.v20i2.4666.

Setiawan, Ferry, \& Dewi, A. A. Sg. Kartika. (2014). Pengaruh kompensasi dan lingkungan kerja terhadap kinerja karyawan pada CV Berkat Anugrah. E-Jurnal Manajemen Unud, 3(5), 1471-1490.

Setyorini, RR. Wahyu, Yuesti, Anik, \& Landra, Nengah. (2018). The Effect of Situational Leadership Style and Compensation to Employee Performance with Job Satisfaction as Intervening Variable at PT Bank Rakyat Indonesia (Persero), Tbk Denpasar Branch. International Journal of Contemporary Research and Review, 9(08), 20974-20985. https://doi.org/10.15520/ijcrr/2018/9/08/570.

Soetikno, Yohanes Johny. (2017). The influence of work environment and organizational culture on work satisfaction and lecturers performance at The Schools of Management Information And Computer In Sulawesi. International Journal of Scientific \& Technology Research, 6(4), 132-136. Retrieved from https://www.ijstr.org/final-print/apr2017/.

Sopiah, Sopiah. (2013). The effect of compensation toward job satisfaction and job performance of outsourcing employees of Syariah Banks in Malang Indonesai. International Journal of Learning and Development, 3(2), 77. https://doi.org/10.5296/ijld.v3i2.3612.

Sugiyarti, Gita. (2012). Pengaruh lingkungan kerja, budaya organisasi dan kompensasi terhadap kepuasan kerja untuk meningkatkan kinerja pegawai (studi pada Fakultas Ekonomi Universitas 17 Agustus 1945 Semarang). Jurnal Ilmiah UNTAG 
Semarang, 1(2), 73-83. Retrieved from https://webcache.googleusercontent.com/search?q=cache:BDsuQOHoCi4J:https:// media.neliti.com/media/publications/9138-ID-perlindungan-hukum-terhadap-anakdari-konten-berbahaya-dalam-media-cetak-dan-

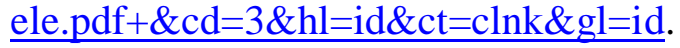

Suryajiwangga, Muhammad Agung Reza. (2017). Pengaruh Budaya Organisasi Dan Kompensasi Terhadap Kinerja Karyawan Dengan Kepuasan Kerja Sebagai Variabel Intervening (Studi Kasus pada PT. Armada Finance Magelang). Jurnal Sains Dan Seni ITS, 6(1), 51-66.

Susetyo, Widyanto Eko, Kusmaningtyas, Amiartuti, \& Tjahjono, Hendro. (2014). Pengaruh budaya organisasi dan lingkungan kerja terhadap kepuasan kerja dan kinerja karyawan Pada PT. Bank Muamalat Indonesia Divisi Konsumer Area Cabang Surabaya. JMM17 Jurnal Ilmu Ekonomi \& Manajemen, 1(1), 83-93. https://doi.org/10.30996/jmm17.v1i01.314. 